\title{
Electronic Shopping Cart For Effective Shopping based on RFID
}

\author{
Kalyani Dawkhar ${ }^{1}$, Shraddha Dhomase ${ }^{2}$, Samruddhi Mahabaleshwarkar ${ }^{3}$ \\ BE Electronics (Pursuing), Electronics Engineering Department of P.D.E.A's COEM, Pune, India ${ }^{1,2,3}$
}

\begin{abstract}
There is huge change in technology, so the rate of people of all ages attracted towards electronic gadgets is increasing. In different type of industries the electronic devices like smart card reader, barcode and RFID scanner having more usage. This type of gadgets also required in supermarkets. In the existing, in the mall every person takes product put into trolley. After the shopping is done that person have to stand in the queue for billing. In the billing process a sell person scan barcode of each and every product and gives final bill. This process is very time consuming and it becomes worst on holidays, special offers or weekends.
\end{abstract}

To overcome that we have been developed a smart way for shopping in malls. Each and every product has RFID tag instead of barcode. The smart trolley will have RFID reader, LCD display. When a person put any product in the trolley it will scan and the cost, name and expire date of the product will display. Cost will add into final bill. Bill will be stored in microcontroller memory. It will transfer from RF transmitter to RF receiver. Receiver will transfer this information to the PC through serial communication. For this project we used Embedded C and VB6.0 software

Keywords: Embedded, RFID tags, reader, Microcontroller LPC2148.

\section{INTRODUCTION}

Shopping mall is a place where most people from all Electronic Product Code. This Electronic Product Code walks of life will get their daily necessities ranging from provides the info like name, price etc about the product. food product, apparels, toiletries; gardening tools electrical When the customer will put the product in the Trolley, the appliances, and others. The numbers of small and large Radio Frequency ID scans the tag and the Electronic shopping malls keep on increasing over the years Product Code number is known by Radio Frequency ID throughout the globe due to the demand of the public. reader. Radio Frequency ID reader passes the Electronic Thus, the level of advancement of shopping mall system Product Code to the ARM 7 micro-controller where ARM and infrastructure also varies. Compared to some foreign 7 compares the Electronic Product Code with the database countries' shopping mall system, there are still plenty of of the system containing various products. After that the spaces for improvement in terms of providing quality name, price and expire date of the product obtained by the shopping experience to the consumers. Consumers often ARM gets displayed on the LCD display of the Futuristic face problems and inconvenience when shopping. These Billing Trolley, where user can see the product problems include worrying that the amount of money information. The ARM 7 microcontroller also passes the brought is not enough for paying all the items wanted, data obtained from the database to the RF transmitter from insufficient information of the items that are for sale and where the data is wirelessly transmitted to the billing also wasting unnecessary time at the cashier. These are the computer. The master computer receives this data through problems that are currently faced by most consumers. RF receiver using Max 232 interface. Max 232 interface is There are some existing methods to solve the problems the interconnection media between the RF receiver and the that are stated above but the effectiveness still consider computer.

improvable. Examples of existing problem solving techniques are substituting the conventional way of keying item per item by hand to the cash register with the technology of barcode scanning where the price are stored in the barcode, and also set up a customer information counter to help the consumer if there are any enquiries about the items at shopping mall.

The problems stated above might eventually be solved or else improved by the implementation of RFID technology in shopping mall. This can be done by simply attach an RFID tag to all the items in shopping mall and attach a RFID reader with a LCD display on the shopping trolley can solve all the problems above.

\section{SYSTEM DESIGN}

Block Diagram

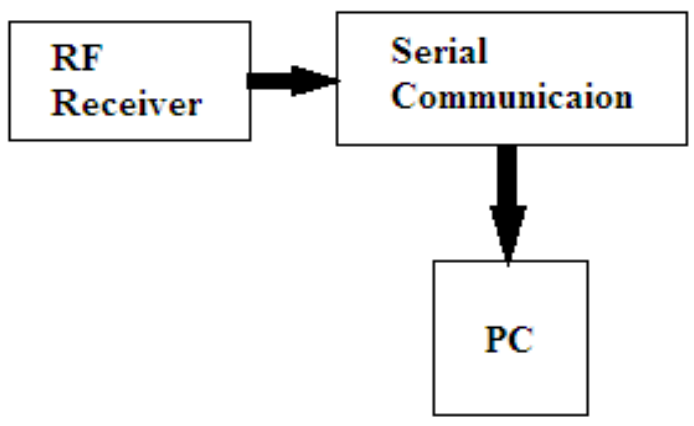

Fig.1 Block Diagram of Server Section

An In our Trolley system, each product will have the passive Radio Frequency ID tag which is bearing a unique 


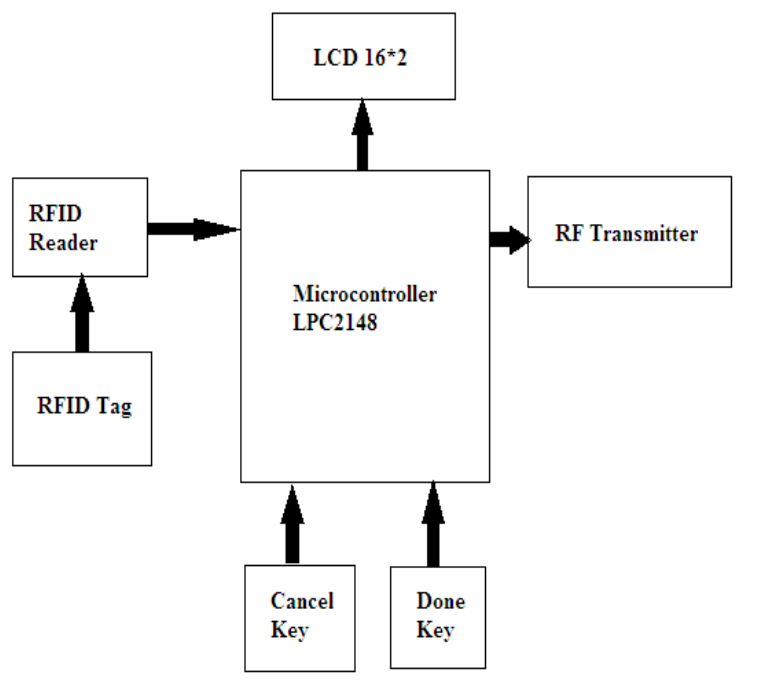

Fig.2 Block Diagram of User Section

1. Trolley Unit

In this unit the ARM processor is attached to a RFID reader and barcode reader. As the user puts the items in the trolley the reader on the trolley reads the tag and sends a signal to the ARM processor. The ARM processor then stores it in the memory and compares it with the lookup table. If it matches then it shows the name of item on LCD \&also the total amount of items purchased.

2. Billing Unit

As soon as the shopping is over the user comes near the billing section. The total bill will display on the billing computer.

3. RFID Tags

Tags are of two types: passive tags which have no battery life and active tags which have battery life. RFID tags released for automatically identifying a person, a package or an items. These are transponders that transmit information. RFID tag contains two parts. One is integrated circuit for modulating, storing and processing information and demodulating radio frequency (RF) signal. The second is an antenna for receiving and transmitting signal.

\section{RFID Reader}

RFID reader consists of an RF module that acts as a transmitter and receiver of radio frequency signal. Transmitter consists of an oscillator to create the carrier frequency; a modulator to make impact on data commands upon this carrier signal \& a receiver that contains demodulator to extract the data returned.

\section{LCD Display}

LCD has the ability to display numbers, characters \& graphics. The display is interfaced to $\mathrm{I} / \mathrm{O}$ port of microcontroller.

RF Module

$\mathrm{RF}$ module consists of RF transmitter and RF receiver. It is a small electronic circuit used to transmit and receive radio signal. It selects one out of a number of carrier frequencies. Types of RF module are:

1) Transmitter module

2) Receiver module

3) Tran receiver module

Copyright to IJIREEICE
In this project we have used Tran receiver type RF module. It is a small PCB sub assembly and is capable of transmitting and modulating a radio wave that carries data. Transmitter modules are implemented alongside a microcontroller which will provide data that can be transmitted to the module.

6. The software consists of two parts

a) Embedded $c$ that is used by the hardware that is RFID receiver (fitted in trolley) and transmitter (RFID tags) that look ups up the specified table of item and maps the product with price.

b) VB is used on the front end to display the final billed amount to the customer on both the display on the trolley and display exit where the final payment is made.

\section{III.SYSTEM FLOW}

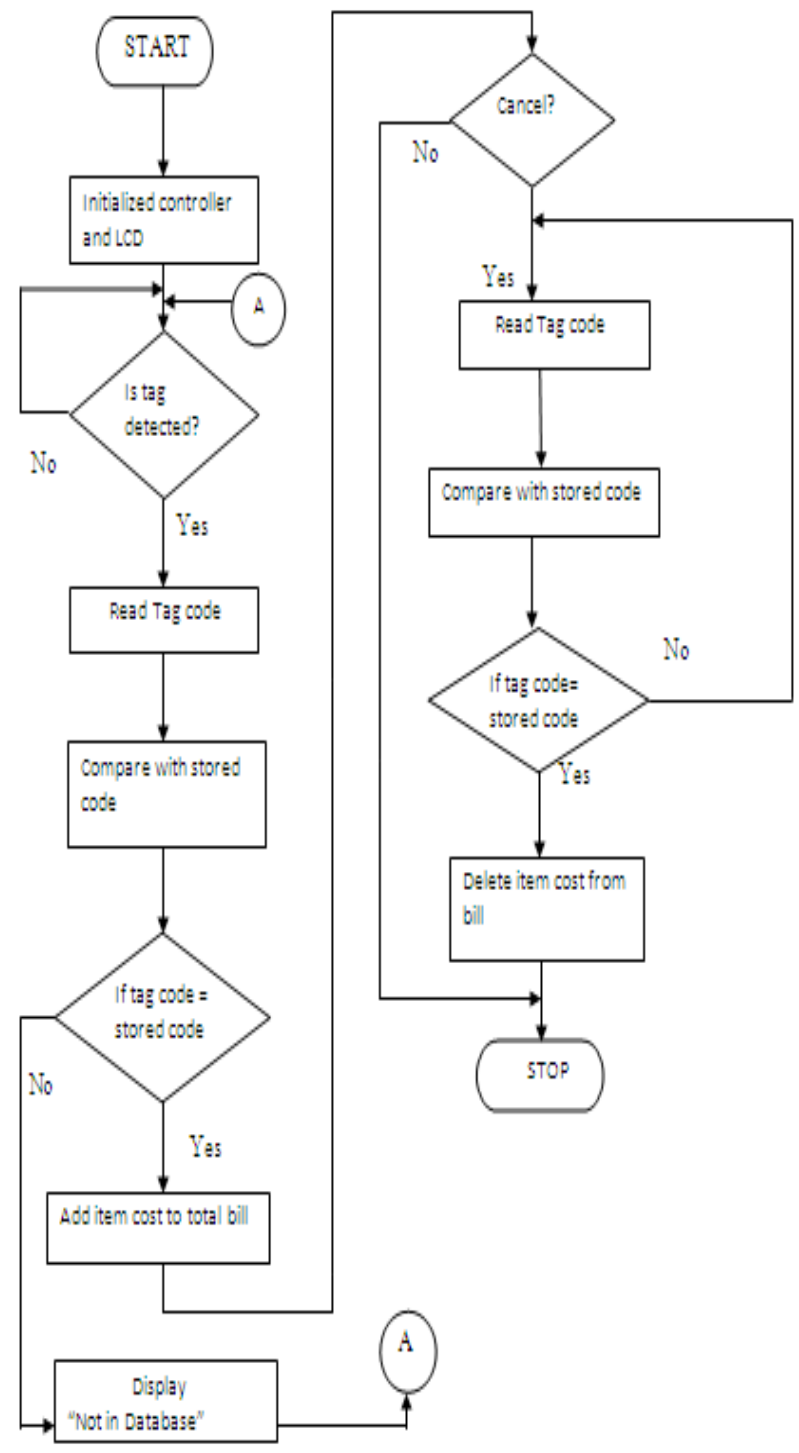

Fig.3 System Flow 


\section{A. Algorithm}

Steps:

1. Start

2. Initialize microcontroller and LCD.

3. Detect RFID tag code and check with stored code.

4. Add cost of product to total bill.

5. If any product is removed then the cost will subtracted from total bill.

6. After done button pressed. The bill will transfer to $\mathrm{PC}$.

\section{IV.APPLICATION}

The main application of this system is at shopping malls to reduce the billing time and enhancing the shopping joy.

1. The application is that it can also be used at Jewelers shop with some modifications.

2. It can be used anywhere like shopping markets where the barcodes are used to good solution which avoids barcode technology.

\section{Conclusion}

In this paper we conclude that, the time required for billing in the shopping malls is reduced by self scanning process also we deduct the product from the trolley as well as keep eye on shopping budge. We also get expire date of a product as we scan it. Thus the precious time of each customer consumed during billing at billing counter is reduced.

This system can be more advanced by using GPS, ZigBee and other communication system.

\section{REFERENCES}

[1] Dr. P. Muthu Kannan, Anupriya Asthana, "Automatic Retail System Using RFID”, Volume 1, Issue 5, October 2013, International Journal of Advance Research in Computer Science and Management. Studies.

[2] Zeeshan Ali, Reena Sonkusare, "RFID Based Smart Shopping and Billing", International Journal of Advanced Research in Computer and Communication Engineering Vol. 2, Issue 12, December 2013

[3] Raju Kumar, K. Gopalakrishna, K. Ramesha, "Intelligent Shopping Cart", International Journal of Engineering Science and Innovative Technology (IJESIT) Volume 2, Issue 4, July 2013.

[4] Satish Kamble, Sachin Meshram, Rahul Thokal, Roshan Gakre, "Developing a Multitasking Shopping Trolley Based On RFID Technology", International Journal of Soft Computing and Engineering (IJSCE) ISSN: 2231-2307, Volume-3, Issue-6, January 2014

[5] Varsha Jalkote, Alay Patel, Vijaya Gawande, Manish sBharadia, Gitanjali R. Shinde, Aaradhana A Deshmukh "Futuristic Trolley for Intelligent Billing with Amalgamation of RFID and ZIGBEE", International Journal of Computer Applications (0975 - 8887) International Conference on Recent Trends in engineering \& Technology - 2013(ICRTET'2013)

[6] J.S.Awati, S.B.Awati, "Smart Trolley in Mega Mall", International Journal of Emerging Technology and Advanced Engineering (ISSN 2250-2459, Volume 2, Issue 3, March 2012)

[7] Dr.K.V.K.K.Prasad, "Embedded/Real time operating systems",. Dreamtech Publications 2010 Edition.
[8] J.Suryaprasad, B.O.P. Kumar, D. Roopa and A.K. Arjun, "A Novel Low-Cost Intelligent Shopping Cart", IEEE 2nd International Conference on Networked Embedded Systems for Enterprise Applications, pp.1-4, 2011.

[9] Mingyan Li, , Rainer Falk paper on "multi-domain access control using asymmetric key based tag reader mutual authentication", Dreamtech Publications 2012 Edition.

[10] American Time Use Survey, http://www.bls.gov/tus/charts.

[11] http://www.cisco.com/web/about/ac79/docs/retail/Mashop-। survey-metrics_UNITED-STATES. PDF 